\title{
Re: "Named Reporting and Mandatory Partner Notification in New York State: The Effect on Consent for Perinatal HIV Testing"
}

This letter is in response to an article published in the June 2002 issue of the Journal of Urban Health [79(2):238-244] titled, "Named Reporting and Mandatory Partner Notification in New York State: the Effect on Consent for Perinatal HIV Testing," by Dolbear et al.

The authors found that the percentage of maternity patients attending a tertiary care labor-and-delivery unit located in Central New York who had received prenatal human immunodeficiency virus (HIV) testing decreased in the months following New York's HIV reporting and partner notification law. In addition, the percentage of women who had not received prenatal care increased following implementation of the law. Based on these results, the authors concluded that "[ $t]$ here is a strong indication that the institution of named reporting and mandatory partner notification has significantly impacted the willingness of pregnant women to undergo HIV testing and prenatal care." $1(\mathrm{p} 238)$

The findings from this study do not warrant this conclusion. First, the authors assumed that decreases in HIV testing and prenatal care observed following the implementation of New York's HIV reporting and partner notification legislation were due to the law itself. However, their study design, an observational, beforeand-after methodology, clearly does not permit the establishment of a cause-andeffect relationship. Second, their findings do not permit generalization beyond the one study hospital and beyond the limited time frame under investigation. Third, the authors used an incorrect date for program implementation of HIV reporting in New York. The program was implemented June 1, 2000, not July 1.

An important limitation of a before-and-after study design is the inability to rule out other causes of the observed findings. For example, the authors noted, but did not offer an explanation for, the statistically significant demographic differences between the pre- and postlaw populations of maternity patients admitted to the hospital. Those in the postlaw population were significantly more likely to be nonwhite, smokers, high school graduates or less, on Medicaid or uninsured, unemployed, and living in an urban residence. Although the authors "controlled" for these variables in their multivariate analyses, it is impossible to know how these or other unmeasured differences between the pre- and postlaw populations may have accounted for their findings. Overall, these considerations suggest that changes in the population served at the clinic before and after the time of implementation of HIV reporting, not the law itself, may be responsible for the changes in the observed prenatal care and prenatal HIV testing rates.

The authors did not discuss the mechanism(s) by which New York's HIV reporting and partner notification law would discourage women from seeking prenatal care. Since HIV testing in prenatal care is voluntary, it seems unlikely that HIV 
reporting would serve as a deterrent to receiving prenatal care. In addition, most women were probably unaware when HIV reporting went into effect. Data from surveys of other populations in New York indicate that even populations expected to be sensitive to confidentiality concerns with HIV reporting, such as injection drug users and gay men, had limited knowledge or concerns about the law or its implementation, even in New York City (New York State Department of Health, unpublished data, 2000, 2001).

Finally, New York State Health Department data indicate that the rate of acceptance of HIV testing among women in prenatal care increased, and rates of no prenatal care in both HIV-positive and HIV-negative women in New York decreased, during the time frame of Dolbear et al.'s study, both statewide and in Central New York. These trends have continued. Data on the approximately 20,000 women giving birth each month across New York State reveal a steady increase in HIV testing during pregnancy, from 83.1\% in December 1999 to $93.4 \%$ by December 2001. Similarly, data from Central New York hospitals also show an increase in prenatal HIV testing, from $94.1 \%$ in December 1999 to $96.8 \%$ by December 2001. The proportion of pregnant women with HIV in New York receiving prenatal care has increased steadily each year, and prenatal transmission rates were the lowest on record in $2000 .^{1}$

New York's HIV reporting and partner notification law is an important public health tool for better tracking of the HIV/AIDS (acquired immunodeficiency syndrome) epidemic and for increasing the availability of voluntary HIV partner notification in New York State. The statewide data available to us show no adverse impact of HIV reporting on prenatal care or prenatal HIV testing rates. Our findings are in accord with other data cited by the authors. ${ }^{2,3}$

\section{REFERENCES}

1. Birkhead G, Wade N, Zielinski M, Glaros R, Warren B, et al. Decline in perinatal HIV transmission in New York state (NYS), 1997-2000. 2002 International AIDS Conference, Barcelona, Spain. July 6-12, 2002.

2. Dolbear GL, Newell LT. Consent for prenatal testing: a preliminary examination of the effects of named human immunodeficiency virus reporting and mandatory partner notification. J Public Health Manage Pract. In press.

3. Rivero Y, Fernandez MI, O'Sullivan MJ, et al. Effect of name reporting on HIV testing rates among women in prenatal care in Miami [abstract]. Int Conf AIDS. 1998;12:873. Abstract 43129.

Guthrie S. Birkhead James Tesoriero Nancy Wade New York State Department of Health 